\title{
Soledad y filosofía. Las críticas de Diderot a Rousseau en el Essai sur les règnes de Claude et de Néron, et sur les mœurs et les écrits de Sénèque
}

\section{(Solitude and philosophy. Diderot's critique of Rousseau in the Essai sur les règnes de Claude et de Néron, et sur les mœurs et les écrits de Sénèque)}

\author{
Adrián RATTO
}

Recibido: 10 de mayo de 2013

Aceptado: 24 de marzo de 2014

\section{Resumen}

El objetivo del trabajo es demostrar, frente a lo que en general consideran los especialistas, que las críticas que Diderot dirige a Rousseau en el Essai sur les règnes de Claude et de Néron desbordan el plano biográfico, hundiendo sus raíces en estructuras centrales de la filosofía del francés. Esto, por otra parte, arroja luces sobre el lugar que la figura de Séneca ocupa en el libro y sobre las críticas que Diderot había hecho al filósofo romano en 1745.

Palabras clave: Naturaleza, soledad, estoicismo, Diderot, Rousseau.
Abstract
The aim of this paper is to demonstrate, contrary to what experts generally con- sider, that the criticism that Diderot has directed at Rousseau in the Essai sur les règnes de Claude et de Néron goes beyond the biographical level, and it is deeply 
rooted in central structures of Diderot's philosophy. This, on the other hand, sheds light on the place Seneca occupies in the book and on the criticism that Diderot had made to the Roman philosopher in 1745.

Keywords: Nature, solitude, stoicism, Diderot, Rousseau.

\section{Introducción}

En 1745, en el Essai sur le mérite et la vertu, Diderot criticó duramente a Séneca. Mucho tiempo después, en 1777, Naigeon y d'Holbach le encargaron una "vida de Séneca" para coronar la traducción al francés de los trabajos del filósofo romano realizada por $\mathrm{M}$. de La Grange y el mismo Naigeon. La obra se publicó en diciembre de 1778, bajo el título de Essai sur Sénèque le philosophe, sur ses écrits et sur les règnes de Claude et de Néron, y se reeditó con agregados en 1782 con el nombre Essai sur les règnes de Claude et de Néron, et sur les mœurs et les écrits de Sénèque, pour servir d'introduction à la lecture de ce philosophe ${ }^{1}$. Allí, Diderot vuelve a ocuparse del autor de De tranquillitate animi, pero en esta ocasión para hacer su defensa.

Por mucho tiempo olvidado ${ }^{2}$, el Essai sur les règnes de Claude et de Néron ha suscitado en los últimos años el interés de los diderotistas ${ }^{3}$. No obstante, como señala Pierre Chartier en la presentación de un número dedicado exclusivamente al trabajo, el Essai es aún un libro poco estudiado 4 . Los trabajos realizados hasta el momento han abierto un fecundo campo de investigación, pero todavía existen muchas lagunas en los estudios. Uno de los temas que aún no ha sido suficiente-

\footnotetext{
${ }^{1}$ El Essai sur les règnes de Claude et de Néron es un libro complejo en el que se mezclan, entre otras cosas, las voces de Diderot y de Séneca, las discusiones de la época de Nerón (I d.C.) y las del siglo XVIII francés. Hace algunos años Paolo Casini decía acerca del Essai: "es una obra compleja, difícil de comprender y de colocar dentro de una justa perspectiva sin la ayuda de un trabajo preliminar acerca de las fuentes y sin un estudio detallado de las variantes entre los dos textos, en resumen, sin una edición crítica, con la que aún lamentablemente no contamos", Casini (1979), p. 238. Afortunadamente en la actualidad contamos con una edición crítica realizada en 1986 por Jean Deprun, Jean Ehrard, Annette Lorenceau y Raymond Trousson: Diderot (1986), pp. 1- 441. Ésta es la edición que utilizaremos en este trabajo.

2 Uno de los más destacados biógrafos de Diderot, Arthur Wilson, por ejemplo, se refiere despectivamente al libro y dice que "quizás hubiera sido mejor que no lo escribiese", cfr. Wilson (1985), p. 578. La trad. es nuestra.

${ }^{3}$ En 2004 la revista Recherches sur Diderot et sur l'Encyclopédie dedicó un número (n ${ }^{\circ}$ 36) al Essai. Asimismo, el número 32 de la revista Diderot Studies, publicado en 2012, contiene el dossier "Le dernier Diderot: autour de l'Essai sur les règnes de Claude et de Néron", que reúne numerosos trabajos sobre el libro. Se podría mencionar también un trabajo más lejano en el tiempo: Conroy (1975).

4 Cfr. Chartier (2004), p. 5.
} 
mente analizado es la naturaleza de las críticas que Diderot dirige en ese trabajo a Rousseau. En general los especialistas circunscriben esas críticas dentro del plano biográfico. Jean Ehrard, por ejemplo, se refiere a las críticas como una "digresión" motivada por una vieja disputa personal entre Diderot y Rousseau. Por esa razón, afirma que "cualquiera sea la interpretación que se realice de estas páginas, debe evitarse considerar estas críticas a Rousseau como la razón de ser del Essai"5. Franco Venturi parece otorgar mayor importancia a las críticas, colocando en éstas el germen del trabajo, sin embargo también reduce la disputa al plano histórico-biográfico. En efecto, según Venturi, la crítica de Diderot no se habría desencadenado por diferencias entre los sistemas filosóficos de los pensadores, sino por el modo de proceder de Rousseau en determinadas ocasiones, el cual habría "contribuido a dividir y debilitar el partido de les philosophes"6. También Paolo Quintili inscribe las críticas en el plano biográfico; por esa razón, decide dejarlas de lado para ocuparse de otros temas del libro "más precisamente filosóficos"7. El objetivo de este trabajo es mostrar que esas críticas, a pesar de lo que consideran los especialistas, hunden sus raíces en importantes estructuras filosóficas que recorren diferentes trabajos del editor de la Encyclopédie, desbordando así el plano histórico-biográfico. Esto, por otra parte, arrojará luces sobre el papel que representa Séneca en el libro y sobre la distancia que separa el Essai sur les règnes de Claude et de Néron del Essai sur le mérite et la vertu, donde Diderot se había ocupado también, como ya señalamos, del filósofo romano.

El trabajo consta de tres partes: en primer lugar (i) se evaluará el alcance de las críticas que Diderot despliega contra Rousseau en el Essai sur les règnes de Claude et de Néron; en segundo lugar (ii), se examinarán, a la luz de (i), las razones que llevaron a Diderot a invertir su valoración respecto de la figura de Séneca en el período que va desde el Essai sur le mérite et la vertu hasta la publicación del Essai sur les règnes de Claude et de Néron. Finalmente (iii), se analizará, a partir de (i) y (ii), cuáles fueron los motivos que, en una serie de pasajes aislados del libro, llevaron al autor de Jacques, le fataliste a poner en riesgo la figura Séneca-Diderot.

\section{Diderot y Rousseau: "deux frères ennemis"8}

En 1756, luego de publicar su Discours sur l'origine et les fondements de l'inégalité parmi les hommes (1755), Rousseau abandona los salones de París para insta-

\footnotetext{
5 Ehrard (1986), p. 15. La trad. es nuestra.

6 Venturi (1992), p. 16. La trad. es nuestra.

7 Cfr. Quintili (2004), p. 31.

8 El título remite al célebre trabajo de Jean Fabre "Deux frères enemies: Diderot et Jean-Jacques", Fabre (1961), pp. 155-213.
} 
larse en el Ermitage, una humilde casa en el campo situada en el valle de Montmerency, ofrecida por su amiga Mme. d'Épinay. Las personas más cercanas al ginebrino, Grimm y Diderot, intentaron disuadirlo de su alejamiento de la sociedad y la coterie holbachique se burló de su proyecto9. Grimm reprochó a Mme. d’Épinay la propuesta que había hecho a Rousseau: "os aconsejo, señora, que intentéis disuadir a Rousseau de pasar el invierno en el Ermitage; estoy seguro que enloquecerá" 10 . Rousseau, no escuchando a sus amigos ni atendiendo a las críticas, decide pasar el invierno en el Ermitage11.

Un año después Diderot publica Le fils naturel (1757). Allí, se puede leer la siguiente sentencia: "el hombre de bien vive en sociedad, sólo el canalla vive en soledad"12. Rousseau cuenta en las Confessions (1782-1789, publicación póstuma) el dolor que sintió al leer, en el ejemplar que el mismo Diderot le había enviado, el pasaje señalado ${ }^{13}$. Jean-Jacques, sintiéndose identificado, reacciona y responde a Diderot a través de una carta. Si bien los problemas no se resuelven inmediatamente, una visita de Rousseau a París y una estadía de dos días en la casa de Diderot alcanzan para superar el conflicto. Sin embargo, la discusión resurge meses después a raíz de un viaje de Mme. d'Épinay a Ginebra por cuestiones de salud. Diderot aconseja a Rousseau acompañar a Mme d'Épinay. Rousseau interpreta el consejo como un nuevo ataque a su libertad. Pero la ruptura definitiva no se dará hasta la publicación de la Lettre à D'Alembert. En este trabajo de 1758, cuyo objetivo principal era cuestionar la entrada "GENÈVE", escrita por D'Alembert para el tomo VII de la Encyclopédie, Rousseau dice: "tenía un severo y juicioso Aristarco, ya no lo

\footnotetext{
9 Cfr. Rousseau (1959), pp. 401, 454 y 455. Sobre la relación y los desencuentros entre Rousseau y Diderot, véase Trousson (2011a), pp. 138 y ss; Wilson (1985), pp. 244 y ss.

10 D’Épinay (1818), p. 257. La trad. es nuestra.

${ }^{11}$ No es ésta la primera discusión entre Rousseau y les philosophes. El primer desencuentro se remonta a 1752, momento del estreno de la ópera Le devin du village. La obra, que fue representada por primera vez en 1752 en el castillo de Fontainebleau, delante del rey y su corte, agradó a Luis XV, quien ofreció una pensión a Rousseau. El ginebrino rechazo la pensión, lo cual provocó una discusión con Diderot, cfr. Rousseau (1959), pp. 375 y ss. Sobre la relación entre Rousseau y les philosophes, véase O'Dea (2010) y Garrard (2003).

12 Diderot (1875a) pp. 65, 66. De aquí en adelante las traducciones de los pasajes utilizados de las obras de Diderot son nuestras.

13 "Yo quería entrañablemente a Diderot, tenía por él una profunda estima, y estaba completamente persuadido de que me correspondía con iguales sentimientos. Pero cansado de su infatigable obstinación en contrariar eternamente todos mis gustos, mis inclinaciones, mi modo de vivir, sobre todo lo que sólo a mi me interesaba; irritado de ver a un hombre más joven que yo querer gobernarme por la fuerza como a un niño; disgustado por su facilidad para prometer y su tardanza en cumplir; fastidiado de tantas citas dadas por él sin comparecer a ninguna (...); aburrido de esperarlo inútilmente tres o cuatro veces al mes, los días señalados por él mismo (...), tenía ya lleno mi corazón de agravios. Este último me pareció grave y me hirió más profundamente", Rousseau (1959), pp. 455-456. La trad. es nuestra.
} 
tengo y ya no lo quiero, pero lo echaré de menos"14; y reenvía a un pasaje del libro del Eclesiástico ${ }^{15}$ a través del cual acusa a Diderot de traición16. Lo que había desencadenado la crítica, como explica en las Confessions, fue la supuesta revelación que Diderot habría hecho a Saint-Lambert de una serie de asuntos que él le había contado de modo confidencial17. Hasta aquí las diferencias parecen quedar reducidas al plano histórico-biográfico.

Varios años más tarde, poco después de la muerte de Rousseau, Diderot retoma la discusión en el Essai sur la vie de Sénèque (1778 - la primera edición lleva por fecha, no obstante, el año 1779). En esta ocasión, a diferencia de lo que había ocurrido en el pasado, la crítica es directa. En 1782, Diderot reedita su Essai sur Sénèque le philosophe, sur ses écrits et sur les règnes de Claude et de Néron (1778), bajo el nombre de Essai sur les règnes de Claude et de Néron, et sur les mours et les écrits de Sénèque, pour servir d'introduction à la lecture de ce philosophe. En el $\S 61$ de esta edición, en la que Diderot incluye algunos agregados y las respuestas a las críticas a la primera edición vertidas principalmente en l'Année littéraire y el Journal de Paris, el autor retoma y amplía las críticas a Rousseau. Siendo inminente la publicación póstuma de las Confessions, que amenazaba la reputación del clan de les philosophes, Diderot vuelve a ocuparse del ginebrino. En primer lugar, anticipándose a las revelaciones que estimaba que se harían en las Confessions, Diderot acusa a Rousseau de cometer una calumnia contra sus antiguos amigos y de revelar información que se le había hecho en confidencia18. Los efectos que la revelación de esos secretos podría provocar en familias y grupos de amigos serían, entonces, el motivo de la crítica. Así, el cuestionamiento parece moverse aún en el plano personal y, en consecuencia, no ser más que un paréntesis en el desarrollo del libro, como el mismo Diderot parece sugerir ${ }^{19}$. Sin embargo, luego de responder a una serie de críticas que aparecieron en el Journal de Paris, en el momento de la aparición de la primera edición del libro, Diderot añade, refiriéndose a la estadía de Rousseau en el Ermitage: "la soledad de los bosques lo ha perdido"20. "Yo había

\footnotetext{
14 Rousseau (1889), pp. 108-109. La trad. es nuestra.

15 "Si habéis lanzado la espada contra vuestro amigo, no desesperéis; puesto que hay medios para reparar el daño. Si lo habéis entristecido con palabras, nada temáis, aún podéis reconciliaros con él. Pero el ultraje, el reproche injurioso, la revelación del secreto y la herida hecha a su corazón en la traición, no tiene remedio: él se alejará sin retorno", citado por Rousseau, ibid, p. 108.

16 Cfr. Rousseau (1959), p. 497.

17 Ibidem

18 “(...) ¿Ha, él [Rousseau], calumniado a sus antiguos amigos? ¿Ha dado muestras de ingratitud a las personas que se han preocupado por él? ¿Ha dejado sobre su tumba la revelación de secretos que le habían sido revelados? ¿Este acto indecoroso puede provocar problemas en familias unidas y generar rencores entre personas que se estiman?", Diderot (1986), p. 120.

${ }^{19}$ Luego de desplegar sus críticas a Roussau, Diderot dice: "he dicho todo lo que tenía por decir, ya no retomaré este asunto. Vuelvo, entonces, a Roma (...)”, ibíd., p. 131.
}

20 Ibid., p. 126. 
anticipado ya lo que iba a sucederle”, agrega ${ }^{21}$. ¿Qué había anticipado Diderot? ¿Se mueve Diderot aún en el plano histórico-biográfico?

En La Religieuse, una novela terminada en 1780, pero publicada póstumamente en 1796, se puede leer: “(...) éste es el efecto de la evasión. El hombre ha nacido para vivir en sociedad. Separadlo, aisladlo, sus ideas se fragmentarán, su carácter cambiará, su cuerpo será atacado por mil dolencias y en su espíritu germinarán, como zarzas en campos salvajes, ideas extravagantes. Colocad al hombre en un bosque, allí su carácter devendrá feroz, en un convento, donde la necesidad se une a la dependencia, es aun peor" 22 . Inmediatamente agrega que "la soledad pervierte" 23. Recordemos que la novela se basaba en un caso real, el de Suzanne Simonin, una joven que había sido encerrada en un convento por su familia. La relación entre "soledad" y "perversión" es la misma que aparecía en 1757 en el ya mencionado Le fils naturel: "el hombre de bien vive en sociedad, sólo el canalla vive en soledad"24. Pero ¿qué pasaría si la sociedad estuviera gobernada por malas leyes? ¿El camino del exilio, del alejamiento no se justificaría en ese caso? Aun en ese caso Diderot desaconseja el alejamiento de la sociedad. En efecto, en el Supplément au voyage de Bougainville, un trabajo de 1772, que se apoya en las experiencias relatadas por Louis-Antoine de Bougainville en su Voyage autour du monde (1771), uno de los personajes dice: "criticaremos las leyes insensatas hasta que sean reformadas, pero, hasta que eso suceda, nos someteremos a ellas (...) ser un loco entre los locos es menos problemático que ser un sabio en soledad"25.

Pero, ¿en qué sentido estas críticas a la soledad y el exilio llevarían el cuestionamiento a Rousseau más allá del plano personal, de la coyuntura histórica? ¿No es esta estrategia de Diderot una simple maniobra para justificar su relación con la emperatriz Catalina II de Rusia 26 o para explicar su decisión de no terminar la Encyclopédie en el extranjero pese a los problemas que tuvo en Francia para llevar

\footnotetext{
21 Ibídem.

22 Diderot (1875b), p. 119.

23 Ibid., p. 120.

24 Supra nota 12.

25 Diderot (1875c), p. 249.

${ }^{26}$ La admiración de Diderot por Catalina II había comenzado en el momento en el que la emperatriz le había ofrecido terminar en Rusia la Encyclopédie, que había sido suspendida en Francia. "¡Es en Francia, el país de la civilización, las ciencias, las artes, el buen gusto, la filosofía, donde uno es perseguido! Y es desde lugares alejados, fríos y bárbaros que se nos tiende una mano", dice Diderot en una carta dirigida en 1762 a Mlle. Volland, Diderot (1877), p. 146. En 1765, momento en el que Diderot decide vender su biblioteca para reunir una dote para su hija, Angelique, la emperatriz de Rusia compró su biblioteca por 15.000 libras y, además le otorgó 1.000 libras anuales para que se encargase de mantenerla y actualizarla. Años más tarde, en 1773 Diderot realiza un viaje a Rusia para visitar a la emperatriz Catalina II, su protectora. Acerca de la relación de les philosophes con Catalina II, véase Gorbatov (2006). Asimismo, véase Binoche (2000), pp. 143 - 162.
} 
a término la empresa 27 ? Sin dudas, estos motivos están presentes en la obra, sin embargo los argumentos y las críticas hunden sus raíces en elementos que superan la coyuntura histórica. Nos referimos a la concepción organicista y normativa de la naturaleza que recorre diferentes trabajos del editor de la Encyclopédie ${ }^{28}$. Es verdad que esa idea de naturaleza convive con otra más marcadamente materialista, que es la que aparece en trabajos como el Rêve de d'Alembert (1769) o la Lettre sur les aveugles (1749), no obstante, cabe señalar que Diderot nunca adopta el materialismo radical de La Mettrie 29 , a quien en el Essai sur les règnes de Claude et de Néron califica como "disoluto, impúdico, bufón y adulador"30.

En uno de sus primeros trabajos, el ya mencionado Essai sur le mérite et la vertu $(1745)^{31}$, Diderot dice que "si la naturaleza entera no es más que un único sistema en el que todos los seres se integran, ninguno de esos seres será bueno o malo sino en función de esa totalidad, del cual es una parte"32. Así, explica que el aleja-

27 Cabe recordar que la publicación de la Encyclopédie provocó una fuerte oposición en algunos sectores de la sociedad francesa y que la misma se desarrolló en medio de grandes polémicas. Desde el comienzo de su publicación se formaron dos bandos: por un lado, el poder religioso con los jesuitas al frente, el delfín del rey y sus allegados y una parte de la intelectualidad envidiosa del éxito alcanzado por los enciclopedistas; por el otro, aquellos que eran favorables a la edición de la obra, una parte de la corte, con Madame de Pompadour a la cabeza, el director de la Biblioteca Nacional, Guillaume Malesherbes, la emperatriz Catalina de Rusia y un conjunto de escritores destacados de la época. En 1757, tras un intento de atentado al rey, los enciclopedistas fueron acusados de favorecer a la oposición al rey y aparecieron una serie de libelos, donde fueron atacados y ridiculizados. La obra pasó a formar parte del índice de libros prohibidos por la Iglesia Católica en 1759 (el escándalo producido por la publicación en 1758 de De l'Esprit, de Helvétius, también había afectado a los editores de la Encyclopédie). En ese mismo año se retiraron a los editores los permisos del Estado para seguir publicando la obra y D'Alembert abandonó el proyecto. Además, la obra sufrió varias interrupciones, prohibiciones y casos de censura. Acerca de la historia de la publicación de la Encyclopédie, véase Darnton (1979). Véase también Blom (2010).

28 Cfr. Proust (1962), p. 406; Ehrard. (1963), p. 372.

${ }^{29}$ Acerca de las "luces radicales", véase Israel (2001).

30 Diderot (1986), p. 248. La crítica de "bufón y adulador" remite al papel La Mettrie en la corte de Federico de Prusia, a la que llegó luego del escándalo provocado por la publicación de L'homme machine (1747). Pero, ¿Por qué "disoluto”? Diderot dice que su crítica se justifica en la medida en que La Mettrie no se había ocupado de la verdad y la virtud (cfr. $i b i d$.). En una nota al pie dice: "estas palabras pueden parecer severas, pero son justas. Es difícil ser moderado con un defensor del vicio y un detractor de la virtud", ibíd. Este motivo fue el que lo alejó también de las corrientes escépticas, véase Bourdin (1999), pp. 85 - 97.

31 Es necesario recordar que el Essai sur le mérite et la vertu es, en realidad, una traducción al francés del libro An Inquiry Concerning Virtue or Merit del conde de Shaftesbury. Sin embargo, como el mismo Diderot señala en el prefacio de la obra, la traducción es libre. Por esa razón, se mezclan en el libro las ideas de Shaftesbury y las de Diderot, cfr. Diderot (1875d), p. 16. Según Jean Ehrard, el Essai sur le mérite et la vertu, constituye el punto de partida del pensamiento de Diderot, cfr. Ehrard (1963), p. 369. Franco Venturi, por otra parte, dice que "en el Essai sur le mérite et la vertu es Diderot quien nos habla a través de las palabras de Shaftesbury”, Venturi (1967), p. 47. La trad. es nuestra.

32 Ibid., p. 26. 
miento de la sociedad lleva al hombre a una situación miserable y que ese alejamiento es un acto "contrario a la naturaleza" 33 . Esta idea normativa y organicista de la naturaleza, que recorre la obra del francés ${ }^{34}$, sirve como marco para las críticas a Rousseau en el Essai sur les règnes de Claude et de Néron. Diderot, como ya se señaló, asocia los actos de Rousseau, según él, viles, a su vida en soledad. De allí que lo contraponga explícitamente a la figura de Séneca, presentado, este último, como alguien que se sacrifica en función del interés general ${ }^{35}$. En efecto, mientras que Séneca, el protagonista de la obra, es un personaje comprometido, virtuoso, capaz de sacrificar sus intereses para demorar el desmoronamiento de la sociedad de su tiempo, Rousseau es el egoísta, el fanático, que se aleja de la sociedad y traiciona a sus amigos. Por esa razón, en el Essai sur les règnes de Claude et de Néron Diderot opone Séneca a Rousseau; mientras que este último es presentado como el "santo" de los anti-philosophes, el primero es su propio protector ${ }^{36}$.

La idea normativa y organicista de la naturaleza es un concepto medular de la filosofía de Diderot, en la medida que le permite hacer frente a la superstición, las morales supranaturales y el fanatismo. El alejamiento de la naturaleza, ya sea a través de la fuga, el retorno a los bosques o la vida monástica y ascética, es presentado en la obra del francés como un deslizamiento hacia las religiones reveladas, el fanatismo o el vicio.

\section{Séneca y Diderot}

En el Essai sur le mérite et la vertu Diderot desliza una dura crítica contra Séneca y su época. En una extensa nota al pie colocada al final de este trabajo de juventud, Diderot presenta a Nerón atormentado por los terribles actos cometidos y

\footnotetext{
33 Cfr. ibid., pp. 117-118.

34 Por ejemplo, en el Supplément au voyage de Bougainville (1772), en el que analiza los efectos de la colonización sobre una población aún no alcanzada por la civilización, uno de los personajes del relato afirma, luego de identificar la naturaleza con la felicidad y la virtud, que "el imperio de la naturaleza no puede ser destruido y que, aunque se lo combata, permanecerá", Diderot (1875c), p. 245. Asimismo, en la Réfutation suivie de l'ouvrage d'Helvétius intitulé L'homme (1773-1774), dice que "la naturaleza ha puesto un límite a la desgracia de las sociedades" y que ese "orden es eterno", Diderot (1875e), p. 276. No es distinto lo que afirma en una de sus contribuciones a la obra de Guillaume-Thomas Raynal, Histoire philosophique et politique des établissements et du commerce des Européens dans les deux Indes (1780, $3^{\circ}$ edición): "la naturaleza ha puesto un límite a los hombres más allá del cual hay más por perder que por ganar", Diderot (1995), p. 684. Esta concepción de la naturaleza es la que lo llevó, por otra parte, a mantener una posición dubitativa frente a la idea de "progreso", que otros philosophes defendían con firmeza, véase Papin (1988); Goulemot (1996); Lotterie (2006).

35 Cfr. Diderot (1986), p. 123.

36 "[...] Tenemos cada uno nuestro santo: Jean-Jacques es el santo del censor, Séneca, el mío”, Ibídem.
} 
cuestiona el "vergonzoso silencio" de Séneca frente a los mismos, así como su preocupación por "aumentar su riqueza" antes que por enseñar a su pupilo a actuar de una manera acorde a la virtud37. "Se pensará que trato a este filósofo [Séneca] de una manera un poco dura, pero no es posible, a partir del relato de Tácito [Anales], pensar de otra manera", dice Diderot al final de la nota ${ }^{38}$. En cambio, en el Essai sur les règnes de Claude et de Néron, que es, como ya se señaló, un trabajo de madurez, Diderot ensaya una apología de Séneca frente a las críticas que el filósofo romano había recibido tanto en su época como en los tiempos del propio Diderot ${ }^{39}$. En ese camino las voces de Diderot y Séneca se mezclan, se superponen. Hisayasu Nakagawa afirma que la identificación de "Diderot con Séneca llega hasta los últimos detalles". A partir de allí no duda en señalar: "Séneca-Diderot, DiderotSéneca: aquí la cara y el reverso de la misma moneda" 40 . En el mismo sentido, Franco Venturi señala que Diderot se "esconde detrás de las costumbres y la máscara de Séneca" 41 y Jean Deprun, que la voz de Séneca es al mismo tiempo la voz de Diderot ${ }^{42}$. ¿Cómo se explica el giro de Diderot en el Essai sur les règnes de Claude et de Néron? ¿Se modifica radicalmente la postura de Diderot en ese trabajo de madurez?

Como ya se señaló, uno de los ejes del Essai sur le mérite et la vertu es la idea de una totalidad ético-metafísica a la que Diderot llama "naturaleza". El alejamiento de ese orden convierte a los individuos en seres ruines y miserables. Al comienzo de la segunda parte de ese libro, Diderot señala que mientras que la conformidad de las inclinaciones del individuo hacia el bien general da lugar a la integridad, la justicia y la virtud, "la corrupción, el vicio y la depravación nacen del desorden de las inclinaciones" 43 . Quien se aleja de la sociedad, del bien común, explica, vive en la "inquietud" y la "melancolía", acosado por "ideas tristes", que lo "desgarran" 44. En resumen, el alejamiento de la sociedad lleva al hombre a una situación miserable y ese alejamiento es un acto contrario a la naturaleza ${ }^{45}$. De aquí se desprende la crítica a la época de Claudio, de Calígula, de Nerón y, también, a Séneca. La causa de las sombras de esas épocas es, según el francés, la distancia entre los intereses de los tiranos y los de la sociedad. Si bien más moderada, la crítica a Séneca no corre por carriles diferentes ${ }^{46}$. Séneca es un eslabón más de ese orden desnaturalizado.

\footnotetext{
37 Cfr. Diderot (1875d), p. 118.

38 Ibídem.

39 Cabe recordar que en 1748 La Mettrie publicó su Anti-Sénèque (también conocido bajo el nombre Discours sur le bonheur), donde critica al filósofo romano.

40 Nakagawa (1995), pp. 19, 22. La trad. es nuestra.

41 Venturi (1992), p. 15. La trad. es nuestra.

42 Cfr. Deprun (1986), pp. 25, 26.

43 Cfr. Diderot (1875d), p. 64.

44 Ibídem.

45 Cfr. Ibid., p. 118.

46 Cfr. Ibídem.
} 
La figura de Séneca es presentada con otros colores en el Essai sur les règnes de Claude et de Néron. El filósofo romano ya no es un cortesano preocupado por aumentar sus riquezas, un personaje egoísta que coloca sus intereses por encima del bien común, sino un hombre virtuoso capaz de sacrificar sus intereses para ponerse al servicio de su sociedad. Se puede mencionar, a modo de ilustración, lo que Diderot señala en el $\S 46$ de la primera parte de la obra. Allí, al analizar el papel de Séneca junto al déspota, dice que el hombre firme y honesto "conserva su puesto, ve aproximarse su pérdida, pero no retrocede" 47 . "Eso fue lo que hizo Séneca", agrega inmediatamente 48 . Séneca debía permanecer junto a Nerón, pese a la aversión que éste le causaba. Abandonar a Nerón y librarlo a sus perversos deseos, hubiera representado "una falta grave", dice Diderot 49 . Séneca, conservando su puesto, vela por el bienestar de sus amigos, parientes y de los ciudadanos en general 50 . Asimismo, en el $§ 75$, al evaluar la manera de actuar de Séneca después de la muerte del virtuoso Burro, Diderot se pregunta si éste debería haberse alejado de Nerón y responde: "alejándose, abandonando la sociedad, era posible que el cruel tirano lo olvidara; en cambio, permaneciendo en la corte, donde su presencia incomodaba, donde sus discursos herían a los poderosos, donde se podía advertir su desprecio por los cortesanos, el peligro era evidente" 51 . Una vez más remarca el modo de actuar de Séneca, contrario a sus propios intereses.

Con matices, Diderot mantiene a lo largo de los años la idea de tintes clásicos de la prioridad de la totalidad sobre lo particular, de la necesidad de la armonía entre las partes y el todo, de la prioridad del bien común sobre el particular. Lo que se modifica es el lugar que Séneca ocupa en ese esquema: antes el autor de De brevitate vitae era presentado como parte de un régimen que se había alejado de la totalidad, del bien común, de la naturaleza; en el Essai sur les règnes de Claude et de Néron, en cambio, Séneca es el hombre virtuoso que sacrifica sus intereses en beneficio del bien común. El criterio para evaluar la obra de Séneca sigue siendo la distancia respecto de la totalidad, de la "naturaleza", como se puede observar en el $\S$ 127 , donde señala que debemos seguir los mandatos de la moral del filósofo romano, excepto en el caso de algunos preceptos de su ética que "repugnan a la naturaleza"52. Es decir, el parámetro es el mismo que en 1745, pero se modifica la distancia que separa a Séneca de esa idea normativa de "naturaleza". Por esa razón Diderot se retracta en $\S 118$ de las palabras vertidas en 1745 en el Essai sur le mérite et la vertu: "un joven autor que estimo y a quien puedo dirigirme sin rodeos, ha

\footnotetext{
47 Diderot (1986), p. 91.

48 Ibidem.

49 Ibid., p. 92.

50 Cfr. ibid., p. 94.

51 Ibid., p. 142.

52 Ibid., p. 227.
} 
publicado la crítica más lacónica y violenta que se haya hecho a Séneca (...)"; y luego de reproducir algunos pasajes de la nota al pie escrita por él mismo contra Séneca en el trabajo de 1745, exclama: “¿De dónde has tomado todo esto? ¿Sobre qué apoyas tus críticas? (...). Cuando sientas en el propio cuerpo la lucha del sabio, te sentirás turbado por las injurias que has lanzado contra el más virtuoso y, yo agregaría, el más desdichado de los hombres, si es que se puede ligar la virtud a la desdicha" 53 . Así es como Diderot, sin modificar sustancialmente los conceptos sobre los que se apoya su pensamiento, invierte, más de treinta años después, las palabras vertidas en 1745 contra Séneca.

\section{Diderot, el estoicismo y la naturaleza}

El Essai sur les règnes de Claude et de Néron parece a primera vista un frío tratado erudito enmarcado en la tradición clásica. El libro está dividido en dos partes, la primera, que sigue de cerca los relatos de los historiadores romanos Tácito y Suetonio vertidos en Anales y en Vida de los doce césares respectivamente, está consagrada a la vida de Séneca; la segunda, al análisis de sus obras. Las palabras que el mismo Diderot desliza en la dedicatoria a Naigeon, las cuales encabezan la segunda edición de la obra, parecen alimentar esta interpretación: "se trata [dice Diderot] de examinar sin parcialidad la vida y las obras de Séneca"54. Sin embargo, esta obra se encuentra lejos de ser un mero trabajo académico. Para comprender el alcance del trabajo, es necesario recordar que el mismo se inscribe en el marco de la lucha ideológica que envolvía al salon del barón d'Holbach, al que Diderot concurría asiduamente, contra los círculos conservadores que se oponían a la contaminación política del trabajo académico. En ese marco Diderot convierte a Séneca, forzando en cierta medida sus escritos, en un filósofo comprometido que resiste los abusos del déspota. Como ya se señaló, entre 1773 y 1774 Diderot había realizado un viaje a Rusia para visitar a la emperatriz Catalina II, su protectora, y había regresado de ese viaje completamente desilusionado respecto de la figura de Catalina II. Así, Diderot parece convertirse en Séneca y Catalina en Nerón.

Sin embargo, la relación Diderot-Séneca en el Essai sur les règnes de Claude et de Néron parece ser menos simple de lo aparente. En las primeras líneas de la segunda parte del libro, señala que analizará los trabajos de Séneca de manera imparcial y que "osará en algunas ocasiones contradecirlo" 55 . Al releer una de las cartas de Séneca a Lucilio, en la que el filósofo romano le aconseja exhortar a su amigo a que permanezca en "el reposo", en "el retiro" 56 , Diderot exclama que eso

53 Ibid., p. 204

54 Ibid., p. 35.

55 Ibid., p. 229.

56 Ibid., p. 251. 
no es bueno para la sociedad y concluye: "hay en el estoicismo un espíritu monacal que me desagrada"57. Además, al analizar el tratado De ira de Séneca, luego de constatar que el filósofo estoico niega la naturalidad de la cólera, incluso en casos como el violento asesinato de un ser querido58, exclama: “Cómo Séneca? (...) ¿No? Tú me pides algo imposible"59. Es similar lo que se advierte en el comentario al libro V de De Constantia. Allí, Diderot, luego de contar que Stilpon después del asalto a su ciudad y de haber perdido a su mujer y sus hijas había dicho que no había perdido nada y que Séneca había alabado la actitud de Stilpon, reacciona: "No lo disimularé, las palabras de Stilpon y el comentario de Séneca me indignan [...]. Si tú no has perdido nada, es porque te habías alejado inexplicablemente de todo lo que es querido a los hombres. Si esas cosas no están adheridas al estoico como su vestimenta, entonces yo no soy estoico y me alegro de no serlo; esas cosas son como mi piel, no podría separarme de ellas sin desgarrarme, sin gritar"60.

¿Cómo entender estas críticas al protagonista del libro? ¿Es ésta la misma crítica que Diderot dirigía a Séneca en 1745? No, en el Essai sur le mérite et la vertu, Diderot criticaba a Séneca por su papel de cortesano en la corte de Nerón, en estos pasajes aislados, en cambio, las tensiones se generan cuando Séneca deja de ser a los ojos de Diderot el hombre comprometido que se enfrenta al tirano y se convierte en el discípulo de Zenón. En el $\S 68$ de la segunda parte del libro, al detenerse en el tratado de Séneca, De vita beata, Diderot analiza la idea de "felicidad" a la luz de la doctrina estoica. Frente a la pregunta “¿qué es la felicidad?”, responde: "la conformidad de las acciones a las leyes naturales". Inmediatamente se pregunta si el hombre virtuoso de los estoicos es, en realidad, "el hombre de la naturaleza"; y, luego de repasar las privaciones que el estoicismo impone al hombre, concluye que "no hay doctrina más alejada de la naturaleza que la doctrina de Zenón"61. El estoicismo es una especie de teología, dice Diderot62. De esta manera retoma lo que ya había dicho en 1765 en la entrada "STOICISME ou Secte Stoïcienne, ou zénonisme" de la Encyclopédie. Allí, Diderot señalaba que "los estoicos decían que es necesario oponerse a la naturaleza" y que "la moral cristiana es un zenonismo mitigado" 63. Diderot critica la idea de sabiduría del estoicismo, la apatía del sabio, la rigidez de su moral, su cercanía a la idea de divinidad. El autor de La religieuse encuentra algo antinatural en el estoicismo. Es ésta la razón por la que en la voz "EPICURÉISME ou EPICURISME", dice, luego de señalar que el epicureísmo es la única doctrina de la Antigüedad que logró conciliar la moral, la felicidad del hombre y sus apetitos natu-

\footnotetext{
57 Ibídem

58 Cfr. ibid., p. 316.

59 Ibídem.

60 Ibid., p. 374.

61 Ibid., p. 348.

62 Ibídem.

63 Diderot (1765), p. 526.
} 
rales, que "se llega a ser estoico, pero se nace epicúreo"64. Es decir, cuando Séneca deja de ser el hombre virtuoso y comprometido para convertirse en el estoico, Diderot toma distancia y le dirige la misma crítica que a Rousseau, a saber, el alejamiento de la sociedad es antinatural. Más allá de las tensiones que esto genera al interior del libro, las categorías que apoyan la reflexión de Diderot siguen siendo las mismas: naturaleza, virtud, felicidad y bien general.

\section{Conclusiones}

"Es probable que el historiador de la literatura francesa no se interese por las ediciones del Essai, pero los biógrafos de Diderot encontrarán allí una cantera de información que está lejos de haberse agotado"65, dice Wilson. El Essai sur les règnes de Claude et de Néron no es, sin embargo, como hemos demostrado, ni un simple trabajo académico, erudito sobre la vida de Séneca, ni un mero trabajo autobiográfico; es un tratado de filosofía, que recoge los intereses que atraviesan la obra de Diderot. Pero, ¿por qué la crítica a Rousseau en medio de ese trabajo sobre la virtud? ¿Es un acto ruin, como sostiene Raymond Trousson, la crítica al amigo que había desaparecido poco tiempo antes de la publicación del trabajo 66 ? ¿Carece esa crítica completamente de sentido, como afirma Wilson67? Tal vez sea un acto ruin, pero no carece, en la estructura de la obra, de sentido. En efecto, el cuestionamiento cumple una función central en el trabajo: Rousseau es la contracara de Séneca, el "antifilósofo" Jean-Jacques, según la denominación utilizada por Diderot, es la contracara del filósofo. Así, el cuestionamiento deja de ser un pasaje aislado y carente de sentido, y se conecta con el tema de la obra y con la filosofía de Diderot en general.

Es necesario señalar que, como afirman algunos especialistas, el mismo Rousseau se habría inspirado en la obra de Séneca para escribir algunos de sus trabajos, en particular Émile (1762)68. La relación entre el hombre y la sociedad que se desprende de los trabajos del filósofo estoico habría influido en el pensamiento de Jean-Jacques. Sin embargo, Diderot presenta a Séneca como la contracara de Rousseau. Con ese objetivo desliga al filósofo romano del estoicismo (salvo en algunos pasajes aislados que hemos analizado en III) y lo presenta como un personaje comprometido y virtuoso, capaz de sacrificar sus intereses para favorecer a la sociedad. En cambio, Rousseau es presentado como un hombre atormentado que, alejándose de la sociedad y la naturaleza, se ha "perdido".

\footnotetext{
64 Diderot (1759), p. 784.

65 Wilson (1985), p. 588. La trad. es nuestra.

66 Cfr. Trousson (2011b), pp. 274-5.

67 Cfr. Wilson (1985), p. 577.

68 Cfr. Pire (1953-1955), pp. 57-92; Jimack (1960), pp. 350 y ss.
} 


\section{Referencias bibliográficas}

Binoche, B. (2000): "Diderot et Catherine II", en B. Binoche; F. Tinland (eds.), Sens du devenir et pensée de l'histoire au temps des lumières, Seyssel, Champ Vallon, pp. 143-162

Blom, P. (2010): Encyclopédie. El triunfo de la razón en tiempos irracionales, trad. Javier Calzada, Barcelona, Anagrama.

Bourdin, J. (1999): "Matérialisme et scepticisme chez Diderot", Recherches sur Diderot et sur l'Encyclopédie, 26, pp. 85-97.

BRot, M. (2010): "Diderot historien juge de lui-même dans l'Essai sur les règnes de Claude et de Néron", en M. Leca-Tsiomis; A. Sandrier (eds.), Diderot, l'Encyclopédie et autres études. Sillages de Jacques Proust, Ferney, Centre international d'étude du XVIIIe siècle, pp. 61-80.

CARnevali, B. (2008): "La faute à l'amour-propre. Aliénation et authenticité chez Rousseau", Annales de la Société Jean-Jacques Rousseau, 48, pp. 79-103.

CASInI, P. (1979): "Diderot apologiste de Séneque", Dix-huitième siècle, 11, pp. 235-248.

Chartier, P. (2004): “Présentation", Recherches sur Diderot et sur l'Encyclopédie, 36 , pp. 5-6.

Conroy, W. (1975): Diderot's Essai sur Sénèque, Oxford, Voltaire Foundation.

DARnton, R. (1979): The Business of Enlightenment: A Publishing History of the Encyclopédie 1775-1800, Cambridge, Harvard University Press.

D’ÉPINAY, L. (1818): Mémoires et correspondance de madame d'Épinay, Paris, Brunet.

Deprun, J. (1986): "Introduction", en Euvres complètes de Diderot, ed. Jean Deprun, Jean Ehrard, Annette Lorenceau y Raymond Trousson, Paris, Hermann, t. 25 .

Diderot, D. (1759): “EPICURÉISME ou EPICURISME”, en D. Diderot y J. D'Alembert (eds.), Encyclopédie ou Dictionnaire raisonné des sciences, des arts et des métiers par une société des gens de lettres, Paris, Briasson / David / Le Breton / Durand, t. 7.

DidEROT, D. (1765): "stoicisME ou Secte Stoïcienne, ou zénonisme", en D. Diderot y J. D’Alembert (eds.), Encyclopédie ou Dictionnaire raisonné des sciences, des arts et des métiers par une société des gens de lettres, Paris, Briasson / David / Le Breton / Durand, t. 15.

Diderot, D. (1875a): Le fils naturel, en Euvres complètes de Diderot, ed. J. Assézat; M. Tourneux, Paris, Garnier Frères, vol VII.

Diderot, D. (1875b): La Religieuse, en Euvres complètes de Diderot, ed. AssézatTourneux, Paris, Garnier Frères, vol. V.

DidEROT, D. (1875c): Supplément au voyage de Bougainville, en Euvres complètes de Diderot, ed. Assézat-Tourneux, Paris, Garnier Frères, vol. II. 
Diderot, D. (1875d): Essai sur le mérite et la vertu, en Euvres complètes de Diderot, ed. J. Assézat; M. Tourneux, Paris, Garnier Frères, vol. I

Diderot, D. (1875e): Réfutation de l'ouvrage d'Helvétius intitulé L'Homme, en Euvres complètes de Diderot, ed. Assézat-Tourneux, Paris, Garnier Frères, vol. II

Diderot, D. (1877): Correspondance, en Cuvres complètes de Diderot, ed. Assézat-Tourneux, Paris, Garnier Frères, vol. XIX.

Diderot, D. (1986): Essai sur les règnes de Claude et de Néron, ed. Jean Deprun, Jean Ehrard, Annette Lorenceau y Raymond Trousson, en Euvres complètes de Diderot, ed. Jean Fabre, Herbert Dieckmann, Jacques Proust y Jean Varloot, Paris, Hermann, vol. 25.

Diderot, D. (1995): “Contributions a l'Histoire de Deux Indes", en Euvres, ed. L. Versini, Paris, Laffont, vol. 3.

Domenech, J. (1989): L'ethique des Lumières: les fondements de la morale dans la philosophie française $d u$ XVIIIe siècle, Paris, Vrin.

EHRARD, J. (1963): L'idée de nature en France dans la première moitié du XVIII siècle, Paris, Albin Michel.

Ehrard, J. (1986): “Pourquoi Sénèque?”, en Euvres complètes de Diderot, ed. Jean Fabre, Herbert Dieckmann, Jacques Proust y Jean Varloot, Paris, Hermann, t. 25.

FABRE, J. (1961): "Deux frères enemies: Diderot et Jean-Jacques", Diderot Studies, 3, pp. 155-213.

GARRARD, G. (2003): Rousseau's counter-Enlightenment: a republican critique of the Philosophes, Albany, State University of New York Press.

GAY, P. (1977): The Enlightenment: an Interpretation. The Science of Freedom, New York, Norton.

Gorbatov, I. (2006): Catherine the Great and the French Philosophers of the Enlightenment, Bethesda, Academica Press.

Goulemot, J. (2001): “Temps et autobiographie dans les Confessions: une tentative de réinscription culturelle", Thélème. Revista Complutense de Estudios Franceses, 16, pp. 151-170.

Goulemot, J. (1996): Le Règne de l'histoire. Discours historiques et révolutions XVIIe-XVIII siècle, Paris, Albin Michel.

Israel, J. (2001): Radical Enlightenment. Philosophy and the Making of Modernity 1650-1750, Oxford, Oxford University Press.

JimACK, P. (1960): La Genèse et la rédaction de l'Émile de Jean-Jacques Rousseau, Genève, Voltaire Foundation.

LeCA-Tsiomis, M. (2004): "Diderot et le nom d'ami: à propos de l'Essai sur les règnes de Claude de Néron', Recherches sur Diderot et sur l'Encyclopédie, 36, pp. 98-108. 
LotTerie, F. (2006): Progrès et perfectibilité: un dilemme des Lumières françaises (1755-1814), Oxford, Voltaire Foundation.

MALL, L. (2004): "Sénèque et Diderot, sujets à caution dans l'Essai sur les règnes de Claude et de Néron", Recherches sur Diderot et sur l'Encyclopédie, 36, pp. 43-54.

Mauzi, R. (1965): L’idée du bonheur dans la littérature et la pensée française au XVIII siècle, Paris, Armand Colin.

Nakagawa, H. (1995): "Diderot, homme des lumières", Recherches sur Diderot et sur l'Encyclopédie, 18-19, pp. 13-25.

O’dEA, M. (2010): Rousseau et les philosophes, Oxford, Voltaire Foundation.

PAPIN, B. (1988): Sens et fonction de l'utopie tahitienne dans l'ouvre politique de Diderot, Oxford, The Voltaire Foundation.

Pire, G. (1953 - 1955), "De l'influence de Sénèque sur les théories pédagogiques de J.-J. Rousseau", Annales de la Société J.-J. Rousseau, vol. 33, pp. 57-92

Proust, J. (1962): Diderot et l'Encyclopédie, Paris, Armand Collin.

Quintili, P. (2004): "Le stoïcisme révolutionnaire de Diderot dans 1'Essai sur Sénèque par rapport à la Contribution à l'Histoire des deux Indes ", Recherches sur Diderot et sur l'Encyclopédie, 36, pp. 29-42.

Rousseau J.-J. (1959), Les confessions, en CEuvres Complètes, ed. B. Gagnebin; M. Raymond, Paris, Gallimard, vol. 1.

Rousseau J.-J. (1889): Lettre à D’Alembert sur les spectacles, Paris, Garnier.

Starobinski, J. (1971): Jean-Jacques Rousseau: la transparence et l'obstacle, Paris, Gallimard.

Trousson, R. (1964): “Diderot et l'antiquité grecque”, Diderot Studies, 6, pp. 215 245.

Trousson, R. (2011a): Rousseau, Paris, Gallimard.

Trousson, R. (2011b): Diderot. Una biografia intelectual, trad. José Ramón Monreal, Barcelona, Acantilado.

Venturi, F. (1967): La jeunesse de Diderot (1713-1753), trad. Juliette Bertrand, Genève, Slatkine.

Venturi, F. (1992): "La vieillesse de Diderot", Recherches sur Diderot et sur l'Encyclopédie, 13, pp. 9-30.

Wilson, A. (1985): Diderot: sa vie et son ouvre, trad. Gilles Chahine, Annette Lorenceau, Anne Villelaur, Paris, Robert Laffont.

Adrián Ratto

Universidad de Buenos Aires

Consejo Nacional de Investigaciones Científicas y Técnicas (CONICET)

ga_ratto@yahoo.com.ar 